\title{
Application of Case Teaching Method in Teaching of Engineering Contract Management based on Team Learning
}

\author{
Wu Yumeng ${ }^{1}$ \\ School of Civil Engineering \\ Suzhou University of Science and Technology \\ Suzhou 215009, China \\ wuyumeng@126.com
}

\author{
Wu Yuzhe ${ }^{2}$ Wang $\mathrm{He}^{2}$ \\ Suzhou Xiangcheng Construction Supervision Co. LTD \\ Suzhou 215000, China
}

\begin{abstract}
This paper takes the undergraduate of engineering management as the object and applies case teaching on TL mode in the course of engineering contract management to improve the quality of teaching, and also examines how to design the teaching process and takes the content of contract planning as an example to illustrate the implementation process. We also conduct a questionnaire to check the effectiveness of the teaching process, and the results show that students can better promote learning from each other through comparison and discussion and grasp the course content by this way.
\end{abstract}

Keywords-Engineering Contract Management; TeamLearning (TL); Case Teaching; Teaching process

\section{INTRODUCTION}

As a professional core course in the undergraduate stage of Engineering Management Specialty, the learning of engineering contract management needs the combination of theory and practice. Thus case teaching is often used in this course. Practice shows that case teaching method can cultivate students' innovative spirit, practical ability, teamwork and interpersonal communication ability more effectively compared with other traditional teaching methods [1]. In traditional case teaching mode, teachers often select the corresponding case in advance, and insert case explanation in the process of interpreting the theoretical knowledge, or let the students discuss the case first and then the teacher make a conclusion. Although the traditional case teaching mode can help students to grasp theoretical knowledge to some extent, there are still some limitations. For example, it takes time for students to analyze and discuss cases in class, while class hour of engineering contract management is usually only 32 to 48 . It's impossible to bring too many cases in class. On the other hand, he students in a teaching class have a different ability to accept knowledge, and some of them may just follow the ideas of the teachers and other students, and have no time to think by themselves which will lead to the fact that those students are passively to accept others' opinions. In addition, the cases selected by teachers are often aimed at a certain point of knowledge in the traditional case teaching process, and there is no continuity and systematicness among the cases. Thus, it is difficult for students to enter the role of the case to analyze and solve the problems. Case teaching method based on TL is an improvement and innovation for the traditional case teaching method, in which the students are divided into study groups and the classic cases that can run through the course are selected so that everyone can analyze the cases deeply.

\section{INSTRUCTIONAL DESIGN}

\section{A. Setting up Learning Teams}

In order to carry out teaching better, the number of students in the teaching class should not be more than 60. Students are divided into groups at the beginning of the semester and the size of the team should not be too large or too small. If there are too many people in a team, some students may participate passively while too few can make students unable to complete the tasks on time. Research has been done and the result shows that usually the most effective teams have five to nine members ${ }^{[2]}$. After several rounds of teaching, it was found that it was more appropriate to divide students into groups of five to seven The group leaders can be selected by the team members and all the students will be informed of the purpose, mode, assessment methods and standards of team learning.

\section{B. Selecting Cases}

Cases in the teaching process are generally divided into examples and case analysis ${ }^{[3]}$. Examples are generally used in traditional case teaching and students' participation is relatively low while case analysis allows students to take part in roles so that they can think and solve problems more actively. The selection of such cases needs to consider several factors. First of all, the cases to be analyzed should be universal and special. The cases selected either should be relatively common which won't make students feel out of reach or should have certain particularity so that students can think during the analysis. Secondly, in order to achieve coherence in teaching process, it is best to choose cases with multiple problems and continuity. In addition, it's best to choose the latest cases for too old cases may cause students to lose interest in study. 


\section{Assessment Method}

There are mainly three ways to assess the course: openbook examination, closed-book examination and paper writing. The final evaluation results are usually composed of the final examination results and daily performance. The closed-book examination generally assesses students' mastery of basic theoretical knowledge which may urge students to memorize some theories, but it's hard to measure students' real mastery and application of knowledge. It's difficult for most undergraduate students to innovate when they write papers and the thing they usually do is to sum up the views of others. In addition, papers generally are studied from a certain point, and it is almost impossible to achieve the purpose of assessing the whole learning process. Open book examination can be based on students' comprehensive analysis ability without standard answers, and students can score so long as the answers are reasonable ${ }^{[4]}$. Therefore, the open-book examination is more suitable for this course.

In order to cultivate the students' ability to analyze and solve problems, it is advisable to increase the proportion of normal grades, which can not only better avoid "a test is a sure thing", but also allow students to pay attention to the peacetime learning process and ease the pressure of the final exam.

\section{Appropriate Evaluation Method of Achievement}

An appropriate evaluation method of achievement is needed to be established to promote the learning enthusiasm of team members according to the characteristics of team learning. Taking the engineering contract management course of Suzhou University of Science and Technology as an example, the normal grade is $60 \%$ and the final examination score is $40 \%$. Usually, $50 \%$ of normal grade is closely related to LT. For example, in the case simulation, the LT will work together to complete the assignments and present the results in the form of team report. The composition of homework scores is divided into two parts: half was based on the team's overall performance and the score for each team member is the same; the other half of the score is assessed according to the division of labor. In this way, members of a LT must be actively involved in the task and can effectively prevent free riders. The members of LT will also help and monitor other members to accomplish the task; otherwise it will affect the performance of every members of the LT.

\section{TEACHING PROCESS}

Teachers design the task for the selected cases according to the teaching content, and ask students to role-play around the case with questions. Students solve problems through discussion and cooperation of team members. The whole teaching process is generally divided into four steps. The first step is to familiarize students with the case, and have a preliminary understanding of the case before class. In the second step, teachers teach relevant theories and knowledge points in class and assign tasks. The third step is to analyze and discuss the case in the form of a TL after class to complete the after-school tasks. In the fourth step, the students reported the results of the study in the form of a team, and the teacher made an evaluation summary to lead the students to review the relevant theories again. The teaching process model is as shown in figure 1.

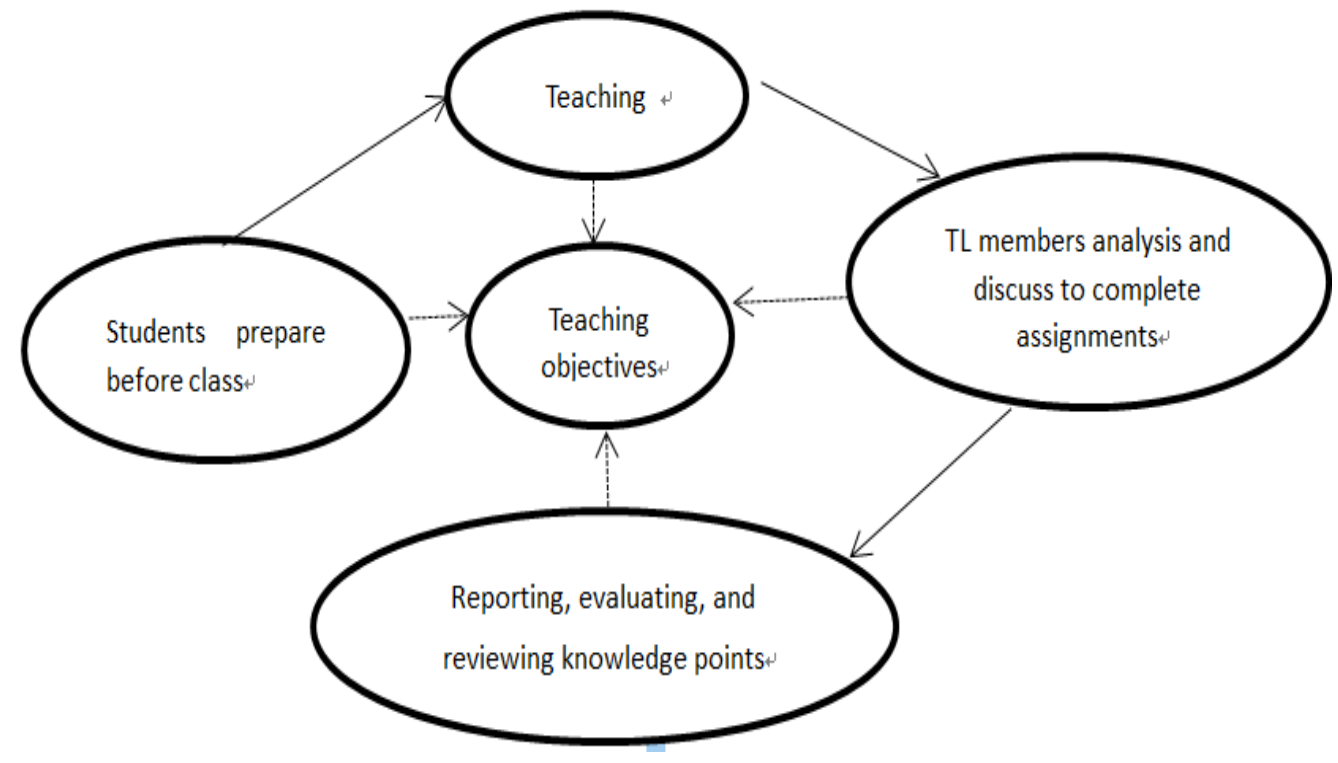

Fig. 1 The process of case teaching based on TL

The following is an example to illustrate the teaching process based on the teaching content of contract planning.

\section{A. Clarifying the Purpose of Teaching}

The teaching content of this part requires students to master the main work contents of the engineering contract planning. Through the study of this part, students can package the project properly, determine the way of contracting and bidding, and draft the contract terms based on the given project data. 


\section{B. Teaching performance in class}

- Preparation before class. Teachers will distribute the courseware, references and relevant case materials to students in advance. The homework is needed to be arranged meanwhile and the setting of the topic should have certain flexibility so that the students have enough space to think. Students need to familiarize themselves with relevant theoretical knowledge and case materials before class and come to class with problems. Project cases given to students will be several different types: infrastructure projects, commercial projects, public facilities projects, real estate development projects, etc. In this way, students can understand the characteristics of contract planning for various types of projects and the problems that need to be paid attention to during contract planning.

- Teaching. The teacher introduces the knowledge points and organizes the students to discuss and speak in class. Then the teacher comments on the speech, and gives answers to solve the student's question. The teacher should also guide the students to read the background information of the case in homework, and remind the students the problems which they need to pay attention to during the completion of the tasks.

- Students complete tasks in a team form. In order to give students enough time to think and prepare homework, students usually be given one or two weeks. Students assign tasks to complete reports and PPT in a team form.

- Report the homework and review. The students submit the report within the specified time, and report it in the form of a team, explaining the ideas and specific practices in the process of project contract planning. After the students' report, the teacher makes comments, points out the shortcomings and mistakes, and guides the students to review the knowledge points again. The teacher should record and analyze the reasons for the students' mistakes and common problems, so as to make corresponding improvement in the next teaching process.

\section{EVALUATION OF TEACHING EFFECT}

The evaluation of teaching effect is the questionnaire for students mainly based on teaching content, teaching method, case selection, students' mastery of the professional knowledge, the improvement of students' professional practice ability, and the training of students' communication. A total of 80 questionnaires were sent out and eighty questionnaires were collected, of which 78 were valid.

The main results of questionnaire analysis are shown in figures 2 to $9.93 \%$ of the students are very satisfied or satisfied with the teaching content; $82 \%$ of the students think that the preparation before class is helpful for learning; $97 \%$ of the students agree that case teaching is helpful to grasp theoretical knowledge and mobilize learning enthusiasm; $87 \%$ of students believe that the selection of cases should focus on practicality and timeliness; $77 \%$ of the students value the authenticity of the cases, and do not want the teacher to revise the real cases in order to highlight the theories; $95 \%$ of the students think the teaching effect is excellent; $85 \%$ of the students think that their professional practice ability is improved through the course; $74 \%$ of students believe that they have improved their communication skills.

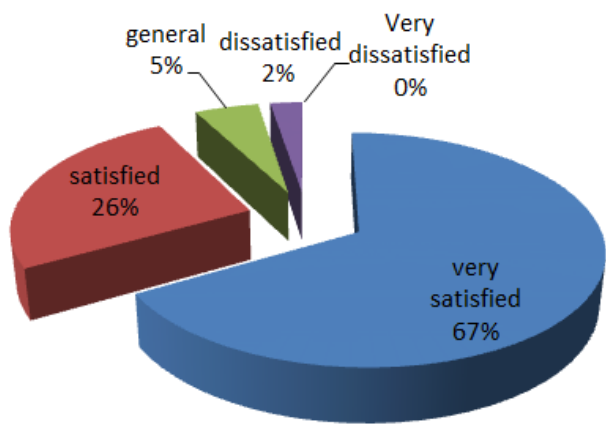

Fig. 2 Satisfaction level of teaching content

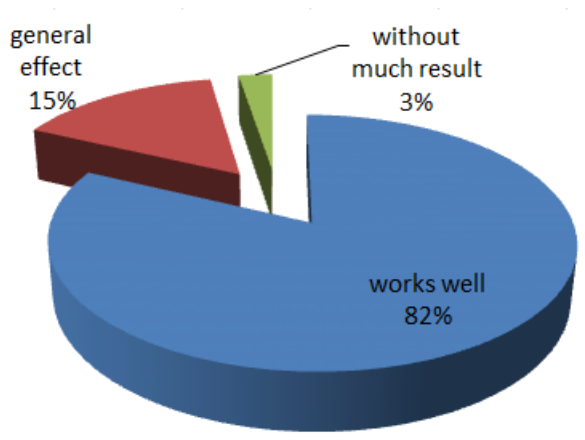

Fig. 3 The influence of pre class preparation

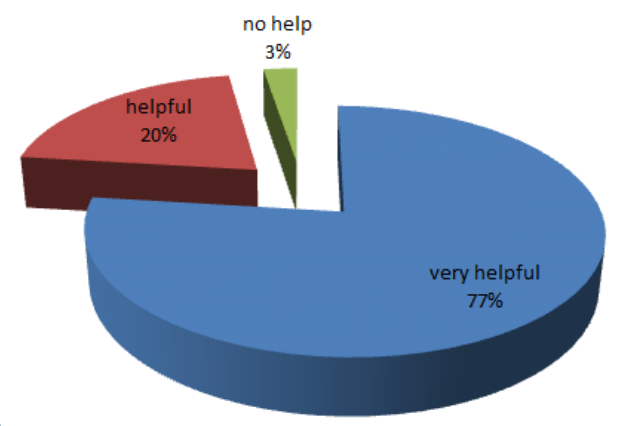

Fig. 4 The help of case teaching to the study of theoretical knowledge 


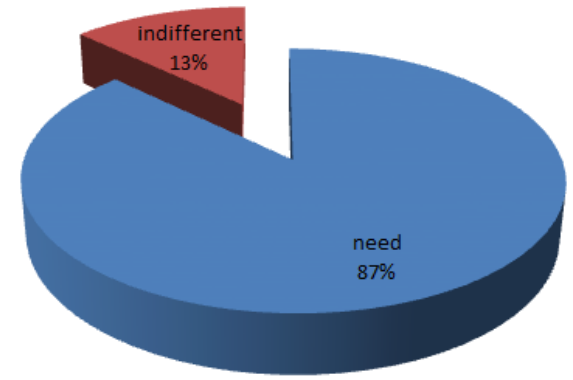

Fig. 5 The practical and timeliness of the case

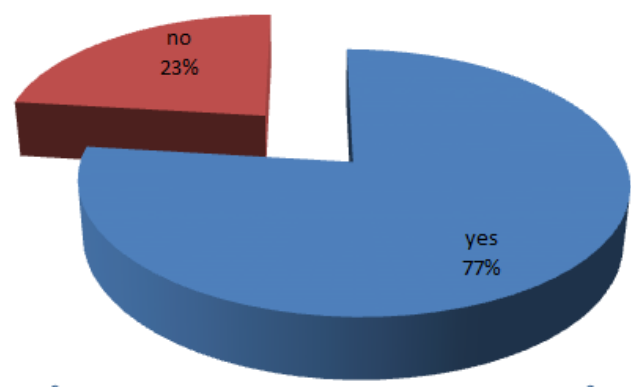

Fig. 6 Whether the authenticity of the case is valued

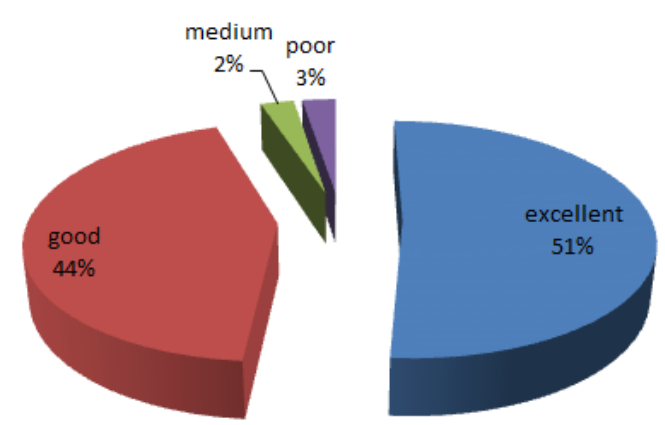

Fig. 7 Evaluation of teaching effect

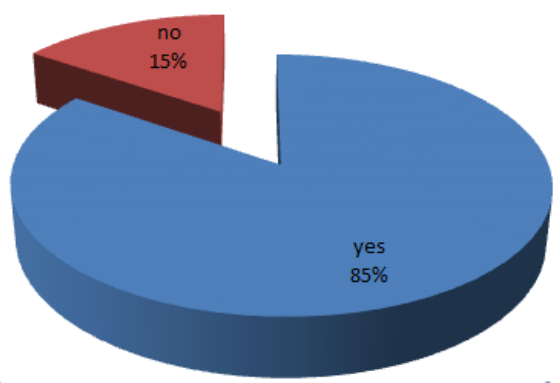

Fig. 8 The improvement of professional practice ability

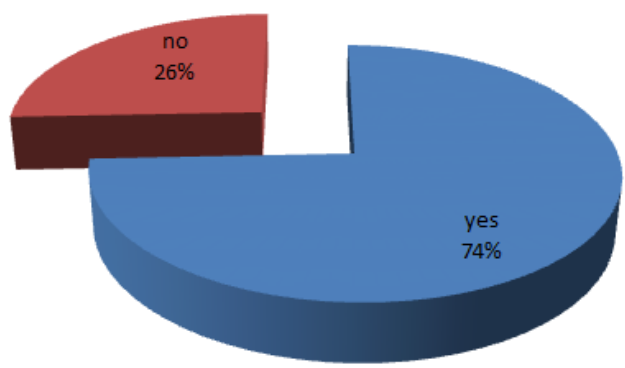

Fig. 9 The improvement of communication ability

\section{CONCLUSION}

In addition to the theoretical knowledge, the cultivation of engineering management undergraduates requires more emphasis on analytical, practical and communication skills in order to meet the demand of the construction market for engineering management talents. The application and effect of case teaching based on TL in engineering contract management course shows that this teaching method is suitable for practical courses. The selection of cases is very important in this way of teaching. The teaching process needs to pay attention to the effect of teaching organization and the participation of students Only by involving all students in the teaching process as much as possible can we achieve the teaching objectives better.

\section{REFERENCES}

[1] Yu Hongjian, Sang Weize, Hao Xin. Research on evaluation methods of classroom case teaching in university [J]. Journal of Ningbo Polytechnic, 2017. 10, pp.48-51.

[2] Stephen P.Robbins, Timothy A. Judge. Orgnizational behavior, 14rd ed., Pearson, 2012, pp. 274.

[3] Xie Xiaozhuan. Sublimation of case teaching method: integration of case teaching and scenario simulation [J]. Academic degree \& graduate education, 2017.01, pp.32-36.

[4] HE Ying, WANG Sheng-wu, BIAN Ke, SHAN Fu-lei. On the examination method of the theory-practice integrated course in universities [J]. Value engineering, 2017.01, pp.168-169. 